\title{
Anticorpos anti-Leptospira spp. em animais mantidos em cativeiro na Paraíba
}

\section{Anti-Leptospira spp. antibodies in captive animals in Paraíba State}

\author{
Arthur Willian de Lima Brasil ${ }^{1}$; Roberta Nunes Parentoni ${ }^{1}$; \\ Roberto Citelli de Farias²; Thiago Ferreira Lopes Nery²; \\ Sílvio Arruda Vasconcellos ${ }^{3}$; Sérgio Santos de Azevedo ${ }^{4 *}$
}

\section{Resumo}

O objetivo do presente trabalho foi verificar a ocorrência de anticorpos anti-Leptospira spp. em animais mantidos em cativeiro no Parque Zoobotânico Arruda Câmara, em João Pessoa, Estado da Paraíba, Nordeste do Brasil. Foram colhidas amostras de sangue de 49 animais: 26 mamíferos das espécies Sapajus libidinosus, Cebus flavius, Saimiri sciureu, Coendu sp., Pseudalopex vetulus, Leopardus pardalis, Leopardus tigrinus, Galactitis vitata, Eira barbara, Nasua nasua, Tayassu tajacu e Ratus norvegicus; 10 aves das espécies Penelope jacucaca, Pavo cristatus, Anodorhynchus hyacinthinus, Ara chlorothpterus, Pionites leucogaster, Polyborus plancus, Geranoaetus melanoleucus e Urubitinga urubitinga; e 13 répteis das espécies Caiman latirostris, Paleosuchus trigonatus, Caiman crocodilus, Tupinabis merinae, Tupinambis teguixin, Boa constrictor, Corallus hortulanus, Python molurus, Bufocephala vanderhaegei, Geochelone denticulata e Geochelone carboraria. Os soros foram examinados pela reação de soroaglutinação microscópica (SAM) utilizando 24 sorovares como antigenos e ponto de corte 1:100. Uma jaguatirica (Leopardo pardalis) apresentou reação positiva para o sorovar Icterohaemorrhagiae com título 100, porém não apresentou qualquer sinal clínico da infecção. Roedores sinantrópicos são os principais reservatórios deste sorovar, o que sugere a necessidade da manutenção e contínua avaliação de programas de controle de roedores.

Palavras-chave: Leptospirose, animais silvestres, zoológico, Nordeste do Brasil

\begin{abstract}
The aim of this survey was to verify the occurrence of anti-Leptospira spp. antibodies in captive animals in the Parque Zoobotânico Arruda Câmara, João Pessoa, Paraíba State, Northeastern Brazil. Blood samples were collected from 49 animals: 26 mammals of the species Sapajus libidinosus, Cebus flavius, Saimiri sciureu, Coendu sp., Pseudalopex vetulus, Leopardus pardalis, Leopardus tigrinus, Galactitis vitata, Eira barbara, Nasua nasua, Tayassu tajacu and Ratus norvegicus; 10 birds of the species Penelope jacucaca, Pavo cristatus, Anodorhynchus hyacinthinus, Ara chlorothpterus, Pionites leucogaster, Polyborus plancus, Geranoaetus melanoleucus and Urubitinga urubitinga; and 13 reptiles of the species Caiman latirostris, Paleosuchus trigonatus, Caiman crocodilus, Tupinabis
\end{abstract}

\footnotetext{
${ }^{1}$ Discentes de Mestrado da Universidade Federal de Campina Grande, UFCG, Patos, PB. E-mail: arthurwillian7@yahoo.com.br; roberta_np@hotmail.com

${ }^{2}$ Médicos Veterinários do Parque Zoobotânico Arruda Câmara, João Pessoa, PB. E-mail: robertocitelli@yahoo.com.br; tflnery@ yahoo.com.br

${ }^{3}$ Prof. Titular da Universidade de São Paulo, UDP, São Paulo, SP. Bolsista de Produtividade em Pesquisa do CNPq. E-mail: savasco@usp.br

${ }^{4}$ Prof. Adjunto IV da UFCG, Patos, PB. Bolsista de Produtividade em Pesquisa do CNPq. E-mail: ssazevedo@cstr.ufcg.edu.br

* Autor para correspondência
} 
merinae, Tupinambis teguixin, Boa constrictor, Corallus hortulanus, Python molurus, Bufocephala vanderhaegei, Geochelone denticulata and Geochelone carboraria. Sera were examined by the microscopic agglutination teste (MAT) using 24 serovars as antigens and cut-off point of 1:100. One ocelot (Leopardo pardalis) presented positive reaction for the Icterohaemorrhagiae serovar with titer of 100, however, it did not show any clinical sign of the infection. Sinantropic rodents are the main reservoirs of this serovar, which suggests the need of maintenance and continuous evaluation of rodent control programs.

Key words: Leptospirosis, wildlife, zoo, Northeastern Brazil

O estudo da cadeia de transmissão das zoonoses é tema atual e deve contemplar as populações de animais silvestres e domésticos. É fato que os animais silvestres têm uma notória importância nesta cadeia, pois alguns deles são os principais reservatórios dos agentes etiológicos deste grupo de doenças. A leptospirose é a zoonose de maior distribuição mundial, presente em todos os continentes, exceto na Antártida (ADLER; MOCTEZUMA, 2010). A doença acomete principalmente os mamíferos, entretanto já foi relatada ocorrência de anticorpos em répteis e aves (SILVA et al., 2010). Sua ocorrência está relacionada, sobretudo, à alta infestação de roedores infectados e às precárias condições sanitárias (FAINE et al., 1999).

Atualmente as leptospiras são classificadas em 13 genomoespécies patogênicas (com mais de 260 sorovares) e em seis saprófitas (com mais de 60 sorovares). Em geral cada sorovar possui um hospedeiro mais adaptado, todavia pode infectar outros hospedeiros (ADLER; MOCTEZUMA, 2010). A transmissão do agente ocorre pelo contato direto ou indireto com urina, água, solo e fômites contaminados, e a bactéria penetra no organismo do hospedeiro pelas mucosas e pele íntegra ou lesada (FAINE et al., 1999).

Nos animais silvestres mantidos em cativeiro nos parques zoológicos, a leptospirose pode se instalar e se disseminar no ambiente com a participação de hospedeiros vertebrados silvestres e sinantrópicos. Levantamentos epidemiológicos em animais silvestres revelaram que animais das ordens Rodentia (roedores), Carnívora (canídeos, felídeos), Primates (macacos), Reptilia (crocodilianos e serpentes) e aves podem apresentar anticorpos para a infecção (HYAKUTAKE et al., 1976; CORRÊA et al., 2004; PIMENTEL et al., 2009; SILVA et al., 2010). Algumas dessas espécies podem se comportar como fontes de infecção, sem apresentar sinais clínicos aparentes ou vão a óbito e o diagnostico só é estabelecido após a necropsia (CORRÊA, 2006). Corrêa et al. (2004) verificaram que no zoológico de São Paulo a prevalência de leptospirose nos animais cativos foi de $19,5 \%$, onde os primatas e os carnívoros apresentaram a maior frequência de infecção; os sorovares predominantemente foram Copenhageni, Pomona e Castellonis.

O presente trabalho teve como objetivo investigar a ocorrência de anticorpos anti-Leptospira spp. na fauna cativa do parque Zoobotânico Arruda Câmara, em João Pessoa, Estado da Paraíba, Nordeste do Brasil. Para tanto foram utilizados 49 animais (Tabela 1).

As amostras de sangue foram colhidas com seringa e agulha descartável em volumes variáveis, por punção do seio venoso occipital, ou das veias jugular, ulnar, cefálica e femoral, de acordo com a espécie de animal. Após o dessoramento, o soro foi transferido para microtubos e congelado. Para a pesquisa de anticorpos contra Leptospira spp., foi utilizado o teste de soroaglutinação microscópica (SAM), de acordo com Galton et al. (1965) e Cole, Sulzer e Pursell (1973), utilizando coleção de antígenos vivos que incluiu os sorovares Australis, Bratislava, Autumnales, Butembo, Castellonis, Bataviae, Canicola, Whitcombi, Cynopteri, Grippotyphosa, Hebdomadis, Compenhageni, Icterohaemorrhagiae, Javanica, Panama, Pomona, 
Pyrogenes, Hardjo (Hardjoprajitno), Wolffi, título do soro foi a recíproca da maior diluição que Shermani, Tarassovi, Sentot, Andamana e Patoc. Os apresentou resultado positivo. Os antígenos foram soros foram triados na diluição de 1:100, e aqueles examinados ao microscópio de campo escuro, que apresentaram 50\% ou mais de aglutinação foram previamente aos testes, a fim de verificar a mobilidade titulados por diluições geométricas de razão dois. $\mathrm{O}$ e a presença de auto-aglutinação ou de contaminantes.

Tabela 1. Animais utilizados no parque Zoobotânico Arruda Câmara, em João Pessoa, Estado da Paraíba, Nordeste do Brasil, segundo a ordem, família, espécie e nome comum.

\begin{tabular}{|c|c|c|c|c|}
\hline Ordem & Família & Espécie & Nome comum & $\begin{array}{c}\text { Número de animais } \\
\text { selecionados }\end{array}$ \\
\hline Crocodylia & Alligatoridae & Paleosuchus trigonatus & Jacaré coroa & 1 \\
\hline Crocodylia & Alligatoridae & Caiman latirostris & $\begin{array}{c}\text { Jacaré do papo } \\
\text { amarelo }\end{array}$ & 1 \\
\hline Crocodylia & Alligatoridae & Caiman crocodilus & Jacaré tinga & 1 \\
\hline Squamata & Teiidae & Tupinabis merinae & Teiú preto & 1 \\
\hline Squamata & Teiidae & Tupinambis teguixin & Teiú branco & 1 \\
\hline Squamata & Boidae & Boa constrictor & Jibóia & 1 \\
\hline Squamata & Boidae & Corallus hortulanus & Suaçu bóia & 1 \\
\hline Squamata & Pythonidae & Python molurus & Píton & 1 \\
\hline Chelonia & Chelidae & Bufocephala vanderhaegei & Cágado cabeçudo & 1 \\
\hline Chelonia & Testudines & Geochelone denticulata & Jabuti tinga & 1 \\
\hline Chelonia & Testudines & Geochelone carbonária & Jabuti piranga & 3 \\
\hline Galliformes & Cracidae & Penelope jacucaca & Jacucaca & 1 \\
\hline Galliformes & Phasianidae & Pavo cristatus & Pavão & 3 \\
\hline Psittaciformes & Psittacidae & Anodorhynchus hyacinthinus & Arara azul grande & 1 \\
\hline Psittaciformes & Psittacidae & Ara chloropterus & $\begin{array}{l}\text { Arara vermelha } \\
\text { grande }\end{array}$ & 1 \\
\hline Psittaciformes & Psittacidae & Pionites leucogaster & $\begin{array}{c}\text { Marininha de cabeça } \\
\text { amarela }\end{array}$ & 1 \\
\hline Falconiformes & Falconidae & Polyborus plancus & Carcará & 1 \\
\hline Accipitriformes & Accipitridae & Geranoaetus melanoleucus & Águia chilena & 1 \\
\hline Accipitriformes & Accipitridae & Urubitinga urubitinga & Gavião preto & 1 \\
\hline Primates & Cebidae & Sapajus libidinosus & Macaco prego & 4 \\
\hline Primates & Cebidae & Sapajus flavius & $\begin{array}{l}\text { Macaco prego } \\
\text { galego }\end{array}$ & 3 \\
\hline Primates & Cebidae & Saimiri sciureus & Mico de cheiro & 1 \\
\hline Rodentia & Erethizontidae & Coendu sp. & Ouriço & 1 \\
\hline Carnivora & Canidae & Pseudalopex vetulus & Raposa do campo & 2 \\
\hline Carnivora & Felidae & Leopardus pardalis & Jaguatirica & 4 \\
\hline Carnivora & Felidae & Leopardus tigrinus & Gato do mato & 1 \\
\hline Carnivora & Mustelidae & Galictis vittata & Furão & 2 \\
\hline Carnivora & Mustelidae & Eira Barbara & Irara & 1 \\
\hline Carnivora & Procyonidae & Nasua nasua & Quati & 5 \\
\hline Artiodáctilos & Tayassuidae & Tayassu tajacu & Cateto & 1 \\
\hline Rodentia & Muridae & Ratus norvegicus & Rato & 1 \\
\hline Total & $\ldots$ & $\ldots$ & $\ldots$ & 49 \\
\hline
\end{tabular}

Fonte: Elaboração dos autores. 
Dentre os 49 animais examinados, uma jaguatirica (Leopardo pardalis), macho, com um ano de idade, foi soropositivo para o sorovar Icterohaemorrhagiae com título 100, contudo não foi detectado nenhum sinal clínico indicativo de infecção por Leptospira spp. Esse animal convivia no seu recinto com uma fêmea da mesma espécie, e a área circunvizinha era composta por três ambientes que abrigavam dois gatos do mato (Leopardus tigrinus), um mico de cheiro (Saimiri sciureus) e duas raposas do campo (Pseudalopex vetulus). Embora esses animais tenham sido soronegativos, alguns trabalhos conduzidos no Brasil relataram a ocorrência de soropositivos (GUERRA NETO et al., 2004; PIMENTEL et al., 2009; COSTA, 2010).

O sorovar Icterohaemorrahgiae é comumente encontrado em roedores, que são os seus hospedeiros de manutenção (CORRÊA et al., 2004). No Parque Zoobotânico Arruda Câmara, em João Pessoa, existe um sistema de controle de roedores sinantrópicos, no entanto, o animal soropositivo nunca teve contato com ambientes além do parque, sugerindo que a infecção ocorreu por contato direto ou indireto com urina de roedores infectados. Por trás do ambiente onde esse animal permanecia havia uma área de mata atlântica preservada que albergava inúmeras espécies silvestres, incluindo roedores, e levandose em consideração que os alimentos consumidos pelos animais de cativeiro serem dispostos no chão, os roedores podem ser atraídos e consequentemente contaminarem a água e os alimentos, criando um ambiente propício para a disseminação da infecção.

Corrêa et al. (2004) realizaram inquérito sorológico em 302 animais do zoológico da cidade de São Paulo e encontraram frequência de animais soropositivos de $19,5 \%$, resultado superior ao do presente trabalho. Por outro lado, a grande maioria dos animais soropositivos foram felinos, e dentre estes, quatro jaguatiricas, sendo um deles reagente para o sorovar Icterohaemorrhagiae. Os autores afirmaram que, no zoológico de São Paulo, o controle de roedores era deficitário, sendo possível inclusive a visualização dos mesmos transitando a luz do dia (CORRÊA et al., 2004). Já no Estado de Mato Grosso, Vieira (2009) examinou seis jaguatiricas de vida livre no pantanal, das quais uma foi soropositiva para o sorovar Icterohaemorrhagiae.

Ainda não se conhece a importância das aves na epidemiologia da leptospirose. Os resultados do presente trabalho corroboram os obtidos por Esteves et al. (2005) no zoológico de Uberaba, que não observaram animais soropositivos dentre 30 aves examinadas. Contudo, no zoológico de Ribeirão Preto, Silva et al. (2010) examinaram 112 aves e encontraram 37 soropositivas para os sorovares Patoc, Copenhageni e Panamá, com títulos variando de 40 até 1280, sendo o sorovar Patoc o mais frequente $(51,3 \%)$.

Nas condições em que o presente trabalho foi executado pode-se constatar que no Parque Zoobotânico Arruda Câmara, em João Pessoa, Estado da Paraíba, a frequência de animais em cativeiro soropositivos para Leptospira spp. foi baixa. No entanto, a ocorrência de reação para o sorovar Icterohaemorrhagiae desperta para a necessidade de manutenção e contínua avaliação de programas de controle de roedores, tendo em vista que este sorovar é mantido por roedores sinantrópicos, em particular o Ratus norvegicus, e já foi demonstrado no Brasil a existência de linhagens de roedores resistentes aos rodenticidas anticoagulantes (BRASIL, 2002).

\section{Referências}

ADLER, B.; MOCTEZUMA, A. P. Leptospira and leptospirosis. Veterinary Microbiology, v. 140, n. 3-4, p. 287-296, 2010.

BRASIL. Manual de controle de roedores. Brasília: Fundação Nacional de Saúde, 2002. 132 p.

COLE, J. R.; SUlZER, C. R.; PURSELL, A. R. Improved microtechnique for the leptospiral microscopic agglutination test. Applied Microbiology, Washington, v. 25, n. 6, p. 976-980, 1973.

CORRÊA, S. H. R. Leptospirose. In: CUBAS, Z. S.; SILVA, J. C. R.; CATÃO-DIAS, J. L. (Ed.). Tratado de animais selvagens. São Paulo: Roca, 2006. p. 736-741. 
CORREAA, S. H. R.; VASCONCELLOS, S. A.; MORAIS, Z.; TEIXEIRA, A. A.; DIAS, R. A.; GUIMARÃES, M. A. B. V.; FERREIRA, F.; FERREIRA NETO, J. S. Epidemiologia da leptospirose em animais silvestres na Fundação Parque Zoológico de São Paulo. Brazilian Journal of Veterinary Research and Animal Science, São Paulo, v. 41, n. 3, p. 189-193, 2004.

COSTA, S. M. Frequência de anticorpos contra Leptospira spp. e Trypanosoma cruzi em primatas neotropicais mantidos em cativeiro. 2010. Dissertação (Mestrado em Ciência Animal) - Universidade Federal Rural da Amazônia, Belém, PA.

ESTEVES, F. M.; GUERRA-NETO, G.; GIRIO, R. J. S.; SILVA-VERGARA, M. L.; CARVALHO, A. C. F. B. Detecção de anticorpos para Leptospira spp. em animais e funcionários do Zoológico Municipal de Uberaba, MG. Arquivos do Instituto Biológico, São Paulo, v. 72, n. 3, p. 283-288, 2005.

FAINE, S.; ADLER B.; BOLIN, C.; PEROLAT, P. Leptospira and leptospirosis. 2. ed. Melbourne: MediSci, 1999. $272 \mathrm{p}$.

GALTON, M. M.; SULZER, C. R.; SANTA ROSA, C. A.; FIELDS, M. J. Application of a microtechnique to the agglutination test for leptospiral antibodies. Applied Microbiology, Washington, v. 13, n. 1, p. 81-85, 1965.

GUERRA NETO, G.; GIRIO, R. J. S.; ANDRADE, T. M.; KOPROSKI, L. P.; MORAES, W.; SANTOS, L. C. Ocorrência de anticorpos contra Leptospira spp. em felídeos neotropicais pertencentes ao criadouro de animais silvestres da Itaipu Binacional e ao Zoológico Municipal Bosque Guarani, Foz do Iguaçu, Estado do Paraná. ARS Veterinaria, Jaboticabal,v. 20, n. 1, p. 75-80, 2004.

HYAKUTAKE, S.; BIASE, P.; SANTA ROSA, C. A.; BELLOUMINI, H. E. Contribuição ao estudo epidemiológico das leptospiroses em serpentes do Brasil. Revista do Instituto de Medicina Tropical de São Paulo, SÃO PAULO, v. 18, N. 1, p. 10-16, 1976.

PIMENTEL, J. S.; GENNARI, S. M.; DUBEY, J. P.; MARVULO, M. F. V.; VASCONCELLOS, S. A.; MORAIS, Z. M.; SILVA, J. C. R.; EVÊNCIO NETO, J. Inquérito sorológico para toxoplasmose e leptospirose em mamíferos selvagens neotropicais do Zoológico de Aracaju, Sergipe. Pesquisa Veterinária Brasileira, Seropédica, v. 29, n. 12, p. 1009-1014, 2009.

SILVA, C. S.; GÍRIO, R. J. S.; GUERRA NETO, G.; BRICH, M.; SANTANA, L. A. S.; AMÂNCIO, F. H.; MARIANI, J. R.; WESSORT, P. M. F. Anticorpos antiLeptospira spp. em animais selvagens do zoológico municipal de Ribeirão Preto, estado de São Paulo, Brasil. Brazilian Journal of Veterinary Research and Animal Science, São Paulo, v. 47, n. 3, p. 237-242, 2010.

VIEIRA, A. S. Levantamento de Leptospira spp.em animais silvestres do Pantanal Sul-Mato-Grossense por meio de técnicas sorológicas e moleculares. 2009. Dissertação (Mestrado em Ciência Animal) Universidade Federal do Mato Grosso do Sul, Campo Grande, MS. 
